\title{
PEMIKIRAN EKONOMI AL-GHAZALI DALAM TEORI KEWANGAN
}

\author{
Mohd Faiz Mohamed Yusof,a,b* Joni Tamkin Borhan, ${ }^{a}$ Nurhanani Romli, ${ }^{a}$ \\ a Jabatan Syariah dan Ekonomi, Akademi Pengajian Islam, Universiti Malaya, Kuala Lumpur \\ ${ }^{b}$ Akademi Pengajian Islam Kontemporari, Universiti Teknologi MARA (UITM), Shah Alam \\ *Corresponding author: mrfaizyusof@gmail.com \\ Article history \\ Received: 2015-12-26 \\ Received in revised form: 2016-01-20 \\ Accepted: 2016-01-20
}

\begin{abstract}
Al-Ghazali (1055 till 1111) was a leading thinker who has made several idea related to finance, such as evolutionary theory of money, function of money, the prohibition of money hoarding, currency issues and the roles of government in a monetary system. Furthermore, the use of the currency at present often causes a variety of unhealthy economics situation. Thus, this study will describe the comparison between the roles of money in use today and the roles of money raised by al-Ghazali. Althought there was a fairly long period of time, the existence on the role of money is said to have continuity to the opinion of al-Ghazali. The study will analyze the extent to which the role of money raised by al-Ghazali can be applied to further improve the role of money in different economics system and how it is used to solve various economics problems that hit today.
\end{abstract}

Keywords: Al-Ghazali, Islamic Economics, Islamic Finance, Conventional Economics

\begin{abstract}
Abstrak
Al-Ghazali bermula pada 1055 hingga 1111 merupakan seorang tokoh sarjana yang terbilang yang telah mengemukakan beberapa idea berkaitan kewangan seperti teori evolusi wang, fungsi wang, larangan dalam penimbunan wang, masalah mata wang bercampur, dan peranan kerajaan dalam kewangan. Tambahan pula, penggunaan wang pada masa kini sering menimbulkan pelbagai situasi ekonomi yang tidak sihat. Justeru, kajian ini akan menjelaskan perbandingan antara peranan wang yang digunakan pada hari ini dengan peranan wang yang dikemukakan oleh al-Ghazali. Walaupun terdapat perbezaan tempoh masa yang agak lama, namun hasil kewujudan wang pada hari ini dikatakan mempunyai kesimbungan terhadap pandangan al-Ghazali. Kajian ini turut menganalisis sejauh mana peranan wang yang dikemukakan oleh al-Ghazali dapat diaplikasikan untuk menambah baik peranan wang dalam sistem ekonomi dan membantu memberi alternatif penyelesaian permasalahan ekonomi yang berlaku pada masa kini.
\end{abstract}

Kata kunci: Al-Ghazali, Ekonomi Islam, Kewangan Islam, Ekonomi Konvensional 


\subsection{PENDAHULUAN}

Pemikiran ekonomi Islam merupakan suatu pola pemikiran yang berasaskan kepada al-Quran dan as-Sunnah dan telah dikembangkan oleh para sarjana Islam melalui penulisan mereka. Pemikiran ekonomi Islam merupakan suatu proses ijtihad pemikir Islam yang berdasarkan sumber-sumber hukum dan sumber-sumber sokongan yang lain bertujuan untuk mencari penyelesaian masalah-masalah asas dalam pelbagai termasuk bidang muamalat dan ekonomi yang dihadapi masyarakat Islam. Dengan erti kata yang lain, pemikiran ekonomi Islam menggunakan kaedah ijtihad. Ini bererti pemikiran ekonomi Islam ini bukanlah bersifat tetap dan kaku semata-mata serta tidak relevan dengan perubahan masa. Akan tetapi, pemikiran ekonomi Islam itu merupakan pembentukan pola pemikiran dalam ekonomi menggunakan akal fikiran manusia yang berusaha untuk memahami kandungan al-Quran dan AsSunnah dalam berhadapan dengan persoalan-persoalan permasalahan ekonomi semasa secara realiti pada masa tersebut. Ini jelas mempamerkan pandangan dan pola pemikir Islam dalam menyelesaikan masalah ekonomi berasaskan Al-Quran, al-Sunnah, ijma, qiyas dan maqasid al-syar'iyyah, dan metodologi-metodologi yang berkaitan ijtihad. Ijtihad dalam konteks pemikiran ekonomi Islam merujuk kepada menggunakan sumber-sumber perundangan Islam dan pada masa yang sama turut menjalankan kajian dan observasi mengenai realiti semasa yang mementingkan mendapatkan kemaslahatan dan menolak kemudaratan (al-Durayni, 1988). Malahan, pemikiran ekonomi Islam turut menerima pendekatan metodologi ekonomi konvensional selagimana tidak mengandungi elemen bertentangan syariah seperti riba, ketidakpastian (gharar) atau perjudian (Joni Tamkin Borhan, 2002).

Ini sepertimana dijelaskan oleh Siddiqi (1992) yang berpandangan bahawa idea dan pandangan dikemukakan oleh pemikir-pemikir Islam itu boleh dijadikan asas tetapi perlu disesuaikan dalam menyelesaikan masalah ekonomi semasa. Ini bermaksud al-Quran dan as-Sunnah mesti dijadikan rujukan utama kemudian barulah diikuti pandangan pemikir-pemikir Islam seperti al-Ghazali dan lainlain sarjana pemikir ekonomi Islam. Antara pemikir-pemikir lain dalam ekonomi Islam yang telah mengarang berkaitan ekonomi Islam termasuklah Abu Yusuf dengan karya Kitab al-Kharaj, Abu 'Ubaid yang telah mengarang Kitab al-Amwal, Ibn al-Muqaffa' mengarang kitab al-Adab al-Kabìr, Al-Jahiz telah menghasilkan karya al-Tabassur bi-al-Tijarah, al-Mawardi telah mengarang Al-Ahkam al-Sultania w'al Wilayat al-Diniyya, Ibn Taimiyah menulis Majmu' Fatawa Shaikh al-Islam, Ibn Qayyim mengarang kitab I'lam Al-Muwaqqi'in 'An Rabb Al-'Alamin, al-Shatibi dengan karya beliau Al-Muwafaqaat fi Usul al-Shari'ah, Ibn Khaldun dengan karyanya yang terkenal al-Muqadimah, alTusi dengan karya beliau iaitu Kitab al-Shakl al-Qattā' dengan teori pengiraan moden, Ahmad 'Ali al-Dalaji pula dengan karangan beliau al-Falakah wa al-Maflukun, dan Shah Waliallah al-Dehlawi dengan penulisan beliau Hujjatullah Baligha.

Al-Ghazali merupakan antara tokoh pemikir yang ulung dalam dunia Islam. Kedudukan kesarjanaan beliau diakui sebagai salah seorang dari ilmuan Islam yang menghasilkan banyak karyakarya yang menjadi rujukan sehingga kini. Kebanyakan hasil karya-karya al-Ghazali tertumpu kepada bidang falsafah, ilmu kalam, tasawuf, dan usul fiqh, seperti Ihya Ulumuddin, al-Munqidz min al AdDhalal, Tahafut al-Falasifah, al-Basith, al-Wasith, al-Khulasah, Al-Mankhul, al-Mustashfa, dan Maqasid al-Falasifah. Selain daripada itu, terdapat beberapa karya al-Ghazali turut membincangkan aspek berkaitan ekonomi antaranya persoalan berkaitan peraturan pasaran, penilaian pajakan, tingkahlaku dalam ekonomi yang dibenarkan, harga dan buruh, wang sebagai alat pertukaran, pencetakan wang, perubahan harga, dan etika dalam ekonomi. Kajian ini meneliti penulisan al-Ghazali yang membincangkan berkaitan kewangan yang mampu diketengahkan sebagai suatu rangka, garis panduan, dan teori yang boleh memberi asas dalam menangani isu dan permasalahan ekonomi termasuklah berkaitan kawalan kewangan dalam ekonomi. 


\subsection{TEORI KEWANGAN AL-GHAZALI}

Terdapat beberapa tokoh pemikir awal Islam yang membincangkan isu berkaitan kewangan dan ekonomi kewangan Islam. Ibn Miskawaih pada 1030 membincangkan mengenai idea mata wang sebagai medium pertukaran. Ibn Miskawaih ini juga menerangkan berkaitan standard penilaian emas. Kesinambungan idea dan pandangan Ibn Miskawaih ini kemudiannya telah diteruskan oleh al-Ghazali. Al-Ghazali merupakan tokoh utama yang ditumpukan dalam kajian ini berikutan idea dan pandangan yang dikemukakan oleh beliau dalam lingkungan 1058 sehingga 1111 masihi yang dianggap sebagai pelopor dan pengasas dalam isu kawalan wang dalam ekonomi. Al-Ghazali telah mengemukakan idea dan pandangan yang perlu dipertimbangkan sebagai kerangka asas dalam membantu menyelesaikan masalah ekonomi yang berlaku pada masa kini. Idea dan pandangan al-Ghazali ini seterusnya disambung pula oleh Taqiuddin Ahmad al-Maqrizi pada kurun ke-14. Pandangan dan idea al-Ghazali ini berdasarkan sorotan awal oleh Al-Maqrizi pada 1030 yang turut tidak bersetuju dengan penggunaan standard emas atau penggunaan jongkong emas dan perak dalam pasaran sebagi alat pertukaran untuk aktiviti ekonomi. Al-Maqrizi telah mencadangkan penggunaan wang lain serta memberi pandangan mengenai hubungan penawaran wang dengan kadar inflasi. Idea yang dikemukakan oleh al-Maqrizi ini kemudiannya disambung oleh al-Ghazali yang seterusnya membentuk teori kuantiti wang bertujuan mengawal jumlah wang dalam pasaran. Perbincangan mengenai teori ekonomi kewangan al-Ghazali ini dimulai dengan sorotan mengenai latar belakang al-Ghazali.

\subsection{KEILMUAN AL-GHAZALI}

Al-Ghazali atau nama sebenarnya ialah Abu Hamid Muhammad bin Muhammad al-Tusi al-Ghazali dilahirkan di Tus Khurasan, Iran pada tahun 450 Hijrah bersamaan 1058 Masihi. Al-Ghazali telah menghasilkan 300 buah karya bertulis yang meliputi pelbagai disiplin ilmu seperti logik, falsafah, moral, tafsir, fiqh, ilmu al-Quran, tasawuf, politik, pentadbiran, dan ekonomi. Namun yang masih disimpan sehingga kini hanya sebanyak 84 buah antaranya ialah Ihya 'Ulumuddin, Tahfut alFalasifaha, al-Tibr al-Masbuk fi Nasihat al-Muluk, al-Mustashfa, Mizan al-'Amal (Noraine Abu, 2007). Daripada keseluruhan karya yang dikarang oleh al-Ghazali, Ihya' Ulumuddin merupakan karya yang paling dikenali umum berikutan terdapat banyak penulisan-penulisan lain yang dihasilkan dengan metodologi yang pelbagai sama ada menganalisis, menyokong, dan mengkritik karya Ihya' Ulumuddin yang dikarang oleh al-Ghazali ini. Antara karya berkenaan ialah Ta 'rif al-Ahya bi Fadail al-Ihya' yang dikarang oleh 'Abd al-Qadir al-Idrus yang menyokong kitab Ihya' Ulumuddin. Manakala, karya 'Abd Rahman Ibn al-Jauzi yang bertajuk 'I'lam al-Ahya' bi Aghlaz al-Ihya' pula mengkritik kitab Ihya 'Ulumuddin ini berdasarkan kelemahan-kelemahan tertentu. Menurut Aidit Ghazali (1991), Ihya' Ulumuddin merupakan satu karya penulisan yang unggul kerana kepelbagaian disiplin ilmu yang dihurai dan dibincangkan dalam karya tersebut seperti ibadah, adab, dan muamalah. Dalam bidang muamalah khususnya, kitab Ihya'Ulumuddin ini merangkumi dua aspek utama dalam kehidupan manusia iaitu tingkah laku dan aktiviti ekonomi. Sadeq (1992) pula mengulas bahawa pemikiran ekonomi al-Ghazali ini merangkumi konsep asas tentang gelagat individu sebagai agen ekonomi, konsep harta, konsep kesejahteraan sosial atau maslahah, perubahan pasaran, permintaan dan penawaran, harga dan untung, nilai dan etika pasaran, aktiviti pengeluaran dan hierarkinya, sistem barter dan fungsi wang, dan peranan pemerintah dalam sebuah ekonomi. Menurut al-Ghazali, terlibat dalam aktiviti ekonomi merupakan fardu kifayah dalam kehidupan masyarakat Muslim. Oleh yang demikian, segala aktiviti dalam ekonomi harus didasari dengan objektif untuk mendapatkan kebahagiaan di akhirat atau al-falah. 


\subsection{TEORI EVOLUSI KEWANGAN AL-GHAZALI}

Penggunaan mata wang telah berlaku semenjak zaman Rasulullah saw. Oleh itu, pendapat yang mengatakan bahawa bangsa Arab Quraisy merupakan bangsa jahiliyyah yang kolot dan tidak menggunakan mata wang serta hidup dengan sistem barter sahaja adalah tidak benar. Ini berikutan pada tahun 15 hijrah, mata wang pertama negara Islam mula dikeluarkan oleh Khalid bin al-Walid di Thabariyyah yang merupakan sebuah daerah yang banyak dipengaruhi oleh mata wang asing. Seterusnya, pada tahun 38 hijrah bersamaan 658 masihi, mata wang kedua telah dihasilkan dengan ciri-ciri mata wang Islam oleh Khalifah Abdul Malik bin Marwan dari Bani Umayyah yang memerintah pada 65H-86H bersamaan 685M-705M. Ahmad Shalabi (1974) menyatakan bahawa keputusan mengeluarkan mata wang sendiri dibuat berdasarkan perbincangan dengan para ulama dan sarjana pada masa tersebut. Pengeluaran mata wang sendiri ini mendapat tentangan daripada Romawi yang beranggapan bahawa penghasilan mata wang ini akan merosakkan hubungan Arab dan Rom. Namun begitu, setelah mengambil kira pandangan daripada semua pihak, Abdul Malik bin Marwan bersetuju bagi meneruskan usaha pembuatan mata wang Islam dan melantik pembuat mata wang untuk menghasilkan mata wang yang mempunyai kalimah tauhid, nama Rasulullah SAW, tempat dan tahun dicetak. Mata wang pertama yang bercirikan Islam dinamakan sebagai 'Dimasyqiyyah' yang bersesuaian dengan tempat pencetakan mata wang tersebut iaitu Damasykus. Khalifah mengirimkan mata wang ini ke seluruh negeri dan mengarahkan supaya mata wang Rom dan Parsi akan dibekukan berkuatkuasa serta-merta dan digantikan dengan mata wang Islam yang baru. Peranan mata wang yang baru ini terus diaplikasikan sebagai alat penilai dalam pertukaran yang ditentukan oleh berdasarkan nilai mata wang tersebut. Keadaan ini berlaku semasa zaman Umayyah dan berterusan ke zaman alGhazali. Pemikiran al-Ghazali dalam teori ekonomi kewangan ini dikarang dalam Ihya Ulumuddin berdasarkan evolusi kewangan pada zaman tersebut dan membentuk pandangan yang jelas mengenai teori dan konsep mengenai mata wang dalam ekonomi. Al-Ghazali telah mengemukakan pandangan berkaitan wang berdasarkan pemerhatian dan analisis beliau mengenai situasi kewangan pada masa tersebut.

\subsection{JENIS MATA WANG DI ZAMAN AL-GHAZALI}

Menurut Ahmad Dimyati (2008), terdapat dua jenis mata wang utama yang wujud pada zaman alGhazali iaitu dinar dan dirham. Kedua-dua mata wang ini dibuat daripada emas dan perak. Emas dan perak memiliki kelebihan untuk dijadikan mata wang berbanding logam lain disebabkan emas dan perak memenuhi beberapa syarat untuk dijadikan mata wang. Antara ciri-cirinya ialah emas dan perak ini merupakan suatu benda yang diterima umum untuk melakukan transaksi jual beli. Selanjutnya, emas dan perak mempunyai kestabilan nilai yang baik. Walaupun dalam harga pasaran semasa, nilai emas dan perak tetap berubah tetapi perubahan nilai emas dan perak hanya sedikit, sentiasa stabil dan tidak terlalu meruap nilainya. Sebaliknya, logam lain mempunyai nilai tidak stabil dan akan mengakibatkan kesukaran untuk melakukan transaksi jual beli, pertukaran, dan alat pengukur nilai. Selain itu, wang juga perlu mempunyai bentuk yang mudah dibawa walaupun dalam jumlah yang besar. Mata wang yang digunakan mesti mempunyai bentuk fizikal yang tahan lama dan tidak mudah rosak supaya mampu berada di pasaran dalam tempoh yang lama. Ciri-ciri mata wang yang seterusnya ialah mata wang mestilah sukar dipalsukan untuk memastikan nilainya sentiasa stabil dan terhad dalam pasaran. Mata wang juga perlu disediakan dalam bentuk yang lebih kecil untuk memudahkan proses transaksi dalam jual beli. Jumlah kuantiti mata wang perlu sentiasa mencukupi bagi memenuhi keperluan aktiviti ekonomi dan rupa bentuk mata wang mestilah sama serta digunakan dalam suatu tempoh yang panjang supaya diyakini oleh masyarakat umum. Mata wang juga mestilah mudah disimpan untuk digunakan bagi menjalankan transaksi jual beli pada bila-bila masa sahaja yang dikehendaki. 


\subsection{PEMIKIRAN AL-GHAZALI BERKAITAN NILAI WANG}

Al-Ghazali menyatakan wang tidak mempunyai nilainya tersendiri kerana wang dibuat untuk mengukur nilai barangan lain dan alat pertukaran. Disebabkan itu, Ahmad Dimyati (2008) mengulas pandangan al-Ghazali bahawa wang tidak mempunyai nilainya sendiri berkait rapat dengan masalah permintaan wang, permasalahan riba, dan jualbeli mata wang. Sadeq (1992) pula berpendapat bahawa wang tidak mempunyai nilai dan apa-apa manfaat pada mata wang itu sendiri. Contohnya, manusia memerlukan wang sebagai alat pertukaran kerana manusia memerlukan pelbagai barangan seperti makanan dan pakaian yang masih belum dimilikinya. Namun, manusia mungkin memiliki sesuatu barangan lain melebihi daripada keperluan sendiri. Al-Ghazali (t.th) turut menjelaskan melalui contoh situasi yang mudah difahami ialah seseorang mempunyai za'faran atau kunyit tetapi memerlukan unta sebagai kenderaan atau sebaliknya seseorang memiliki unta tetapi memerlukan za'faran. Dalam keadaan ini, suatu pertukaran perlu dilakukan melalui suatu bentuk ukuran nilai. Tambahan pula, pemilik unta pastinya tidak akan menukarkan seekor unta hanya untuk mendapatkan $z a$ 'faran yang dianggar nilai jauh lebih rendah. Namun, tidak terdapat pengukuran antara unta dan za'faran serta berapa banyak za'faran yang diperlukan untuk seekor unta. Oleh sebab ini, mata wang diperlukan untuk mengukur perbezaan nilai antara barangan atau komoditi untuk memudahkan pertukaran antara manusia. Berikut adalah huraian lanjut mengenai teori kewangan al-Ghazali.

\subsection{PEMIKIRAN AL-GHAZALI MENGENAI FUNGSI WANG}

Al-Ghazali telah mengemukakan beberapa pandangan beliau mengenai fungsi wang dalam ekonomi. Pertama, al-Ghazali memperkenalkan fungsi wang sebagai 'qiyam al-dunya' iaitu wang sebagai alat yang digunakan untuk mengukur nilai barang dan membandingkan dengan barangan lain. Al-Ghazali telah membuat perumpamaan wang dengan sebuah cermin yang tidak mempunyai warna tetapi mampu menunjukkan warna-warna yang lain. Ini menunjukkan bahawa wang secara hakikatnya tidak mempunyai nilai tersendiri tetapi ianya berfungsi untuk mengukur dan menilai barangan lain. Oleh sebab peranan wang untuk mengukur dan menilai barangan lain, al-Ghazali menggelarkan mata wang sebagai 'hakim mutawasit', iaitu wang berperanan sebagai hakim yang adil dalam menentukan harga barang. Ini merupakan salah satu sebab wang dicetak dan diedarkan dalam pasaran untuk digunakan masyarakat dalam aktiviti ekonomi. Fungsi wang kedua ialah at-tabadul atau al-mu'awidah yang bermaksud wang sebagai perantara dalam pertukaran barang. Fungsi ini juga mempunyai hubungan dengan fungsi qiyam al-dunya. Selanjutnya, fungsi mata wang yang lain menurut al-Ghazali ialah alat untuk mendapatkan barangan lain dan tujuan-tujuan tertentu. Sebenarnya, fungsi mata wang sebagai alat untuk mendapatkan barangan adalah berbeza dengan fungsi sebagai alat pertukaran. Ini disebabkan wang dinyatakan sebagai wang membeli barangan tetapi barang tidak membeli wang. Contohnya jika seseorang memiliki sepotong pakaian, maka dia hanya memiliki sepotong kain itu sahaja. Manakala, jika seseorang memiliki sejumlah wang, maka dia sekaligus memiliki wang dan boleh memiliki apa sahaja barangan yang senilai dengannya. Al-Ghazali juga menetapkan beberapa peraturan yang ketat dalam mata wang emas dan perak. Berdasarkan pandangan al-Ghazali berkaitan kewangan, Aidit Ghazali (1991) berpendapat bahawa prinsip kewangan yang dijelaskan oleh al-Ghazali ini bertujuan memastikan kestabilan mata wang emas dan perak sekaligus mengelakkan berlaku perubahan nilai mata wang ini terlalu tinggi atau rendah. Perubahan nilai yang terlalu tinggi atau terlalu rendah akan memberi impak besar kepada mata wang sebagai alat pertukaran, penyimpan nilai, dan unit ukuran nilai. Oleh sebab itu, al-Ghazali mewajibkan setiap wang yang dikeluarkan perlu mempunyai sandaran nilai emas dan perak bagi mengukuhkan fungsi wang dalam pasaran. 


\subsection{PRINSIP EKONOMI KEWANGAN AL-GHAZALI}

Perkara berkaitan kewangan dibincangkan dalam bab sukur (shukr) dalam kitab Ihya' Ulumuddin. Siddiqi (1992) menjelaskan al-Ghazali menbincangkan masalah sistem barter, kepentingan wang, dan fungsinya serta beberapa idea berkaitan. Al-Misri (1981) pula mengulas bahawa al-Ghazali dengan jelas menunjukkan fungsi wang sebagai alat pengukur nilai, alat pertukaran nilai, dan penyimpan nilai. Menurut al-Ghazali, wang tidak diminta disebabkan wang itu sendiri tetapi wang diminta bertujuan untuk mendapatkan barangan lain. Ketika zaman al-Ghazali, wang telah mula digunakan sebagai medium dalam transaksi. Wang dinar dan dirham telah mula digunakan sebagai mata wang rasmi dalam dunia Islam. Al-Ghazali telah menunjukkan mengenai kepentingan mata wang dalam karyanya Ihya' Ulumuddin seperti kata beliau:

"Manusia memerlukan bermacam-macam bahan dalam hal keperluan hidup dan keperluan lain. (Tetapi) kadang-kadang ia tidak mampu mencari keperluan-keperluan tersebut sedangkan saat itu ia memiliki barang yang sedang tidak ia perlukan. Oleh itu diperlukan adanya suatu alat tukar (wang) dan alat pengukur nilai bagi benda-benda yang akan dipertukarkan. Kerana tidak mungkin seseorang yang memiliki unta menyerahkan untanya hanya untuk memiliki za'faran. Lagi pun tidak ada korelasi (hubungan) antara za'faran dengan unta yang dapat menunjukkan perbandingan harga antara keduanya."(al-Ghazali, t.th)

Berdasarkan petikan daripada Ihya' Ulumuddin ini, al-Ghazali menggambarkan kesulitan yang akan dihadapi sekiranya hanya sistem barter berfungsi dalam aktiviti ekonomi. Antara masalah dalam sistem barter ini ialah kesukaran untuk mendapatkan keinginan yang sama antara pembeli dan penjual. Seterusnya, sistem barter ini menyebabkan masalah dari segi kesukaran untuk menentukan nilai sesuatu barangan contohnya adakah sekilo beras mempunyai nilai seekor lembu ataupun memerlukan pembahagian bahagian-bahagian tertentu. Selain itu juga, sistem barter ini menyebabkan masalah iaitu dalam isu kehendak atau pilihan penjual dan pembeli kepada pihak-pihak tertentu serta barangan tertentu. Oleh yang demikian, penggunaan wang merupakan satu keperluan yang utama dalam urusan ekonomi yang bukan sahaja menyelesaikan masalah ekonomi malahan mewujudkan perubahan yang sesuai dengan perubahan masa yang praktikal sehingga masa kini. Perbincangan seterusnya adalah mengenai prinsip ekonomi kewangan dalam dikemukakan oleh al-Ghazali.

\subsection{LARANGAN MENIMBUN WANG}

Dalam kewangan Islam, wang adalah alat yang diperlukan oleh masyarakat umum untuk tujuan ekonomi. Oleh itu, kegiatan menimbun wang akan menghilangkan fungsi wang dan menjejaskan masyarakat. Aktiviti penimbunan mata wang diistilahkan sebagai kanz al-mal dan mengikut istilah ekonomi konvensional dikenali sebagai Money Hoarding. Terdapat juga istilah lain yang dikenali sebagai ikhtikar. Tetapi ikhtikar ini lebih sesuai digunakan untuk aktiviti penimbunan barang. Wang yang ditimbun tidak akan memberi manfaat pada masyarakat contohnya ia akan mengakibatkan kesukaran kepada pengusaha dan pemodal untuk mendapatkan modal bagi menjalankan aktiviti perniagaan dan perusahaan. Ini kerana wang dalam pasaran hanya beredar pada golongan tertentu sahaja. Penimbuhan wang seterusnya akan mengurang keberkesanan usaha dan produktiviti masyarakat. Dalam hubungan ini, al-Ghazali menyatakan bahawa:

"Jika seseorang menimbun dirham dan dinar, dia telah berdosa besar. Dinar dan Dirham selalunya tidak memiliki kegunaan pada dirinya. Dinar dan dirham dicipta supaya diagihkan dari tangan ke tangan, untuk mengatur dan memudahkan pertukaran, sebagai simbol untuk mengetahui nilai barang dan kelas. Siapa pun yang mengubahnya menjadi peralatan-peralatan emas dan perak biasanya tidak bersyukur kepada penciptanya, dan lebih buruk berbanding penimbun wang. Orang yang mengubah emas seolah-olah 
memaksa pemerintah untuk melakukan apa yang tidak sepatutnya seperti mengenakan cukai. Menimbun wang adalah lebih baik berbanding mengubahnya kerana terdapat logam, tembaga, peruggu, besi, dan tanah liat yang dapat digunakan untuk membuat (barangan atau perhiasan). Namun, logam lain (tembaga, tanah dan sebagainya) tidak dapat untuk menggantikan fungsi dijalankan dirham dan dinar."

\section{(Al-Ghazali, t.th)}

Kegiatan menimbun wang bererti menarik mata wang dari beredar dalam ekonomi untuk sementara waktu. Walau bagaimanapun, menimbun wang menunjukkan bahawa wang masih wujud dalam bentuknya dan berkemungkinan untuk beredar semula dalam pasaran. Seterusnya, menimbun wang dan melebur wang untuk dijadikan barangan lain akan mengganggu fungsi wang dalam ekonomi. Menurut al-Ghazali, larangan ikhtikar bersifat mutlak dan berkaitan dengan dua aspek utama iaitu jenis harta yang ditimbun dan waktu ditimbun. Jenis harta yang dilarang ditimbunkan ialah makanan ruji seperti gandum dan padi. Jenis harta yang lain masih dibincangkan oleh para ulama. Dalam masalah kanz al-mal, terdapat dalil yang jelaskan melarang aktiviti tersebut. Al-Maududi (1980) turut membincangkan larangan mengumpulkan harta. Kesan penimbunan harta akan menyebabkan masalah keseimbangan pembahagian pendapatan dalam masyarakat. Manusia yang mengumpulkan harta dan tidak membelanjakan harta bukan sahaja mencampakkan dirinya dalam masalah moral tetapi juga melakukan kejahatan yang besar kepada masyarakat. Kesan penimbunan harta ini akan juga akan kembali memudaratkan dirinya juga. Oleh sebab itu, Islam sangat memerangi penimbunan harta dan sifat bakhil seperti ini sepertimana firman Allah SWT:

Terjemahan: Dan jangan sekali-kali orang-orang yang bakhil dengan harta benda yang telah dikurniakan Allah kepada mereka dari kemurahanNya menyangka bahawa keadaan bakhilnya itu baik bagi mereka. Bahkan ia adalah buruk bagi mereka. mereka akan dikalongkan (diseksa) dengan apa yang mereka bakhilkan itu pada hari kiamat kelak. dan bagi Allah jualah hak milik segala warisan (isi) langit dan bumi. Dan (ingatlah), Allah Maha mengetahui dengan mendalam akan segala yang kamu kerjakan. (mukjizat) yang nyata dan dengan (korban) yang katakan, maka membunuh mereka, jika kamu orangorang yang benar (dalam apa yang kamu dakwakan itu)?

(Surah Ali 'Imran, 2:180)

Rasulullah SAW dalam ini bersabda yang diriwayatkan dari Mu'ammar yang bermaksud, "Tidak ada orang yang menimbun kecuali bersalah', (HR Abu Daud, al-Tirmidzi, dan Muslim)

Seterusnya larangan penimbunan wang (kanz al-Mal) juga terdapat dalam firman Allah SWT:

Terjemahan: Wahai orang-orang yang beriman! Sesungguhnya banyak di antara penditapendita dan Ahli-ahli ugama (Yahudi dan Nasrani) memakan harta orang ramai dengan cara yang salah, dan mereka menghalangi (manusia) dari jalan Allah (ugama Islam). Dan (ingatlah) orang-orang yang menyimpan emas dan perak serta tidak membelanjakannya pada jalan Allah, maka khabarkanlah kepada mereka dengan (balasan) azab seksa yang tidak terperi sakitnya.

\section{(Maksud surah al-Baqarah, 2: 34)}

Berdasarkan ayat di atas, istilah al-dhahab (emas) dan al-fiddah (perak) pada ayat di atas bermaksud mata wang pada waktu ayat tersebut diturunkan. Oleh itu, larangan penimbunan emas dan perak turut dimaksudkan sebagai penimbunan mata wang. Ibn Taimiyyah (1963) menjelaskan ayat tersebut memberikan ancaman terhadap dua jenis tindakan iaitu menimbunkan harta dan tidak menginfakkannya kepada jalan Allah. Menurut al-Ghazali, matlamat larangan menimbun wang adalah kerana tindakan tersebut akan menghilangkan fungsi-fungsi wang. Al-Ghazali menyatakan tujuan wang diwujudkan adalah sebagai alat transaksi agar ia beredar dalam masyarakat dan bukannya 
dimonopoli oleh golongan tertentu sahaja. Al-Ghazali memberikan perumpamaan dengan menyatakan bahawa wang seperti seorang hakim yang adil yang mempunyai tanggungjawab dalam memutuskan berkaitan transaksi. Penimbunan wang seolah-olah memenjarakan pemerintah dan tidak dapat menjalankan tugasnya seterusnya menyebabkan kezaliman terus bermaharajalela.

\subsection{TEGAHAN PENGGUNAAN MATA WANG BERCAMPUR}

Al-Ghazali menjelaskan bahawa kezaliman yang berkaitan dengan mata wang terdapat dua jenis iaitu aktiviti penimbunan wang dan pembuatan wang dengan bahan campuran. Wang campuran disebut sebagai al-zaif. Menurut al-Ghazali, wang campuran yang wujud dalam pasaran akan menimbulkan kerosakan dalam ekonomi masyarakat. Al-Ghazali menyatakan bahawa adalah sesuatu ketidakadilan yang besar untuk menempatkan wang palsu beredar. Semua orang yang telah menerima wang tersebut dalam urus niaga telah zalimi. Al-Ghazali juga menjelaskan bahawa peredaran satu dirham buruk lebih buruk daripada mencuri seribu dirham kerana untuk tindakan mencuri adalah satu dosa apabila dilakukan, tetapi wang buruk yang beredar adalah sebuah tindakan yang mempengaruhi banyak yang pihak yang menggunakan wang tersebut dalam transaksi mereka. Ini jelas menunjukkan al-Ghazali begitu tegas terhadap masalah wang bercampur yang menunjukkan tindakan ini adalah berdosa dan menyebabkan kerosakkan besar dalam ekonomi masyarakat.

Terdapat dua pandangan ulama dalam masalah wang yang bercampur ini. Pertama, wang bercampur dan yang asal telah bercampur digunakan dalam pasaran sehingga tidak dapat dibezakan. Dalam keadaan ini, orang ramai boleh menggunakan wang tersebut. Kedua, sekiranya mata wang tersebut masih boleh dikenali dan dibezakan. Abu Ya'ala (1997) menyatakan terdapat dua pandangan terhadap masalah mata wang bercampur ini. Pertama, dilarang menggunakan wang bercampur yang beredar dalam pasaran. Pendapat ini dikemukakan oleh Muhammad Ibn Urakin, al-Haris, Yusuf Ibn Musa, dan Ja'far Ibn Muhammad. Kedua, dibenarkan menggunakan campuran tersebut dengan hukum makruh. Pendapat ini dikemukakan oleh Qiran Ibrahim Ibn Haris. Pendapat kedua ini membenarkan penggunaan mata wang campuran walau dalam apa keadaaan sekali pun. Menurut pandangan pengikut Syafi'i, jika mata wang yang tulen lebih banyak berbanding mata wang palsu di pasaran, maka harus menggunakan mata wang campuran tersebut. Manakala, jika sebaliknya pengikut Syafi'i berbeza pendapat apabila mata wang bercampur lebih banyak berbanding mata wang asal iaitu suatu pandangan membenarkan manakala satu pandangan lagi melarang menggunakannya (al-Farra, 1994).

Al-Ghazali telah menyatakan beberapa cara atau langkah yang perlu diambil apabila seseorang menghadapi masalah wang bercampur sepertimana berikut:

"Dan hendaknya diketahui bahawa dalam masalah al-zaif (wang buruk) terdapat lima perkara yang harus dilakukan. Pertama, jika seseorang mendapatkan wang campuran atau diberi oleh orang ramai, maka hendaklah dia membuangnya sehingga tidak memungkinkan lagi orang lain mengambilnya. Atau orang tersebut dapat memberikan kepada orang lain atau dapat dimusnahkan wang tersebut sehingga tidak dapat digunakan lagi. Kedua, bagi pedagang (atau aktiviti ekonomi lain) wajib mengetahui tentang wang campuran ini, bukan kerana tujuan kepentingan sendiri tetapi agar tidak mengedarkannya kepada orang lain yang tidak tahu sehingga ia menanggung dosa. Ketiga, jika seseorang menyerahkan wang kepada orang lain dengan memberitahunya terlebih dahulu. Ia tidak bererti dia telah terlepas daripada dosa. Hal ini adalah kerana tindakan itu sama dengan mengedarkan wang palsu kepada orang lain. Namun, jika dia tidak mempunyai tujuan demikian, orang itu hanya menanggung dosa yang dilakukan (tidak akan menanggung dosa akibat peredaran wang tersebut). Keempat, jika seseorang mengambil wang campuran dengan tujuan untuk dimusnahkan, maka hal itu sangat digalakkan. Kelima, yang dimaksudkan dengan wang buruk ianya tidak dibuat daripada emas tulen tetapi 
hanya sepuhan atau campuran sahaja. Namun, jika sesuatu negara secara rasmi membenarkan sah laku wang daripada campuran, maka ia dibenarkan."

(Al-Ghazali, t.th)

Ahmad Dimyati (2008) mengulas lagi bahawa al-Ghazali mendefinisikan wang buruk apabila wang tersebut tidak menggunakan bahan asli atau campuran sama ada emas atau perak. Namun, ia tidak dikatakan sebagai wang buruk sekiranya telah mendapat kebenaran untuk penggunaannya di dalam negara tertentu. Al-Ghazali juga melarang penggunaan wang bercampur dalam aktiviti ekonomi kerana beliau telah menjangkakan terjadinya implikasi buruk daripada peredaran wang bercampur dalam pasaran.

\subsection{LARANGAN PERDAGANGAN MATA WANG}

Ghazanfar (2000) menjelaskan bahawa larangan al-Ghazali terhadap perdagangan mata wang berasaskan kepada larangan aktiviti riba. Al-Ghazali tidak membincangkan masalah riba atas pinjaman-pinjaman wang seperti yang sering dibincangkan dalam masalah riba. Walau bagaimanapun, al-Ghazali menumpukan masalah riba dalam transaksi kewangan akan mengubah fungsi utama wang sebagai alat tukar dan sebagai unit ukuran nilai. Sebagaimana yang dibincangkan oleh sarjana Muslim dan bukan Muslim, larangan riba dalam pinjaman adalah larangan yang mesti ditinggalkan secara keseluruhannya. Namun, al-Ghazali membincangkan daripada perspektif berbeza. Menurut beliau, transaksi riba dalam kewangan mungkin terjadi dalam bentuk yang tersembunyi dan beberapa transaksi ini mungkin berdasarkan syariah, sementara yang lain mungkin tidak berdasarkan syariah. Riba alFadl hanya berlaku ke atas enam jenis barang sahaja iaitu emas, perak, gandum, barli, kurma, dan garam. Sekiranya barangan tersebut diurusniagakan dengan jual beli riba, iaitu jual beli barang dengan barang secara tunai dan melebihkan salah satu daripadanya maka urusniaga tersebut adalah haram sebagaimana yang disebut di dalam hadis berikut:

Maksudnya: Emas dengan emas, perak dengan perak, gandum dengan gandum, barli dengan barli, kurma dengan kurma, dan garam dengan garam. Yang seumpama dengan seumpama, yang sama dengan yang sama, dan tunai dengan tunai. Maka sesiapa yang menambah atau meminta tambahan, ia telah melakukan riba. Apabila jenis ini berlainan salah satu daripada yang lain, maka berjual belilah ikut suka kamu.

(HR Muslim)

Dalam masalah perdagangan mata wang dikatakan sama dengan aktiviti riba iaitu jual beli mata wang. Al-Ghazali secara jelas melarangkan aktiviti perdagangan mata wang ini sepertimana kata beliau:

"Bahawa di larang amalan jualbeli wang adalah kerana jika ini dibolehkan hal itu sama sahaja dengan membiarkan orang yang melakukan aktiviti kanz al-mal (penimbunan wang) yang akan mengakibatkan pada berkurangan wang dalam masyarakat. Kerana dengan sebab jualbeli wang, wang akan beredar pada golongan tertentu, iaitu orangorang kaya yang melakukan amalan tersebut (yang melakukan jualbeli mata wang). Dan ini tidak dapat dinafikan lagi adalah tindakan yang zalim"

\section{(Al-Ghazali, t.th).}

Walau bagaimanapun, al-Ghazali membenarkan jual beli wang yang diperbuat daripada jenis bahan yang berlainan, misalnya dinar dengan dirham. Ini kerana kedua-dua diperbuatkan daripada bahan yang berbeza yang jelas berbeza dari pelbagai segi seperti kualiti dan rupa bentuk. Tambahan pula, pertukaran wang yang berbeza sangat diperlukan untuk aktiviti ekonomi. Ini bertepatan dengan hadis berikut: 
Maksudnya: "Janganlah kalian berjualbeli emas dengan emas dan perak dengan perak kecuali dengan timbangan yang setara. Dan juallah emas dengan perak dan perak dengan emas mengikut kehendak kalian".

(HR al-Bukhari)

Menurut pendapat kebanyakkan fuqaha, emas dan perak merupakan barangan ribawi yang jelas dilarang pertukaran yang sama kerana berlaku riba nasi'ah.

\subsection{PERANAN PEMERINTAH DALAM KEWANGAN DAN INSTITUSI PERBANKAN}

Teori kewangan Imam al-Ghazali turut dikaitkan dengan campurtangan pemerintah dan pembentukkan institusi perbankan. Dalam masalah pembuatan dan pengendalian mata wang, alGhazali menyatakan bahawa kerajaan mempunyai kuasa penuh untuk melaksanakan atau melantik badan tertentu untuk menguruskan hal ehwal kewangan dalam ekonomi, contohnya institusi perbankan. Al-Ghazali turut melarang seandainya kuasa mencetak dan mengendalikan mata wang ini dilakukan oleh sesuatu pihak tanpa mendapat kebenaran daripada pemerintah. Berasaskan kepada prinsip ekonomi Islam, campurtangan pemerintah dalam ekonomi mestilah berlandaskan kepada akidah yang mendorong kepada tindakan yang produktif, sekaligus menjadi kaedah utama yang dilaksanakan untuk membentuk masyarakat yang produktif. Hal ini menjadi kewajipan bagi kesemua lapisan masyarakat untuk mematuhi setiap arahan yang dikeluarkan oleh pemerintah bagi memastikan terbentuknya kesejahteraan dalam kehidupan bermasyarakat. Ini adalah bersesuaian dengan firman Allah:

\section{Terjemahan: "Taatilah Allah, taatilah Rasul dan pemimpin (pemerintah) di antara kamu."}

(Surah al-Nisa', 4:59)

Peranan pemerintah atau institusi rasmi yang menjadi kerajaan bertujuan menjalankan keadilan yang melibatkan keseluruhan masyarakat yang saling bergantungan dan bertukar-tukar mengenai keperluan hidup. Pada peringkat permulaan, peranan kerajaan hanya sebagai pembuat dan pengendali mata wang. Al-Ghazali menyatakan adanya hubungan antara pencetakan wang dengan institusi perbankan yang dipertanggungjawabkan oleh pemerintah. Kata al-Ghazali, "Kemudian timbul lagi keperluan kepada pencetakan mata wang, ukiran dan pengiraan wang. Maka keperluan ini menimbulkan keperluan kepada tempat membuat mata wang dan tempat perbankan (shayarifah)."

Setelah pembuatan wang oleh kerajaan Islam. Penggunaan mata wang Rom dan Parsi tidak lagi digunakan. Namun, satu institusi diperlukan untuk menukarkan mata wang Islam kepada wang Rom dan Parsi bagi kegunaan untuk perdagangan antarabangsa. Oleh sebab itu, institusi perbankan ketika zaman al-Ghazali mempunyai dua peranan yang utama iaitu pertama, menjadi tempat penukaran mata wang untuk mendapatkan mata wang lain. Sementara yang kedua, sebagai perantaraan untuk mengirim wang ke kawasan-kawasan lain. Kebanyakan pekerja bank datang daripada Basrah yang menyediakan urusan perbankan untuk keperluan perdagang-pedagang yang datang daripada penghujung timur daerah barat iaitu Ferghanah di sempadan India sehingga penghujung barat iaitu di Asia. Hasan Ibrahim (1979) menyatakan mata wang yang digunakan ialah mata wang emas dinar dan mata wang dirham perak. Selain itu, terdapat juga mata wang kertas yang diberi nama 'Shakku' yang digunakan seperti cek pada masa kini. Selain itu, berlaku juga transaksi penukaran mata wang. Menurut Hasan Ibrahim (1979), nilai mata wang dinar dan dirham adalah stabil pada masa tersebut tetapi terdapat beberapa perubahan dan perbezaan nilai dinar dan dirham. Nilai mata wang dinar ketika itu bersamaan 14 dirham tetapi berubah dari masa ke semasa dan perbezaan nilai satu tempat dengan tempat lain. Nilai mata wang dinar pernah berubah bersamaan 10 dirham, 13 dirham dan pernah naik bersamaan 15 dirham. 
Idea dan pandangan al-Ghazali dilihat mula membincangkan mengenai teori kuantiti wang. Larangan perdagangan mata wang dan penimbunan mata wang bertujuan menghalang penawaran wang berkurangan. Apabila penawaran berkurangan, ini secara langsung akan mengganggu jumlah transaksi perdagangan. Ini kerana wang tidak menjalankan fungsi sebenarnya iaitu sebagai medium pertukaran untuk mendapatkan sesuatu barangan dan perkhidmatan

Pandangan al-Ghazali ini telah disambung oleh tokoh selepas itu iaitu Ibnu Taimiyyah. Beliau sekali lagi telah menekankan dua fungsi utama mata wang iaitu menentukan nilai dan sebagai medium pertukaran. Ibnu Taimiyyah (1963) menjelaskan bahawa mata wang berfungsi menentukan nilai sesuatu barangan dan jumlah yang perlu dibayar sebagai pertukaran untuk mendapatkan kuantiti barangan yang berbeza. Salah seorang murid beliau iaitu Ibn Qayyim menerangkan dengan lebih jelas bahawa mata wang dan syiling tiada manfaat pada sifat mata wang itu sendiri tetapi digunakan untuk mendapatkan barangan lain (Ibn Qayyim, 1996). Hal ini juga telah dibincangkan oleh al-Ghazali yang menyatakan dinar dan dirham tidak mempunyai nilai dalamannya tetapi digunakan untuk mendapatkan barangan lain. Penekanan terhadap dua fungsi utama wang menunjukkan bahawa al-Ghazali sangat bertegas melarang perdagangan mata wang kerana ini akan mengganggu peranan hakiki mata wang dalam pasaran. Setiap pertukaran mata wang mestilah secara langsung. Ini kerana jika ada satu pihak yang membayar secara langsung manakala satu pihak lagi membayar pada tertangguh, maka transaksi tersebut dianggap tidak sah. Islahi (1992) mengulas pandangan Ibn Taimiyyah yang turut berpendapat pandangan al-Ghazali ini merupakan salah satu sebab mengapa Rasulullah SAW melarang transaksi pertukaran mata wang tetapi salah satu pihak membayar secara tertangguh. Tokoh pemikir Islam dilihat telah mula membincangkan teori kewangan dengan lebih jelas.

Ibn Taimiyyah (1963) menyambungkan ideologi pemikiran al-Ghazali dalam teori kewangan yang menekankan nilai syiling yang berlaku semasa zaman Mamluk Sultan di Mesir. Ibn Taimiyyah telah mengutarakan masalah kepada pemerintah agar meneliti dan memeriksa semula nilai mata wang yang mengganggu aktiviti ekonomi. Beliau menerangkan terdapat masalah nilai pendasar dalam mata wang yang mengakibatkan lebihan pembuatan mata wang dalam pasaran. Beliau juga berpendapat bahawa pihak berkuasa hanya perlu mengeluar atau melombong timah untuk syiling berdasarkan nilai transaksi sahaja untuk mengelakkan ketidakadilan pada masyarakat. Ibn Taimiyyah (1963) mula menunjukkan bahawa terdapat hubungan kuantiti wang, jumlah keseluruhan jumlah transaksi, dan tingkat harga. Beliau menyatakan bahawa jumlah peredaran mata wang timah ini mestilah selari dengan jumlah transaksi dalam pasaran bagi memastikan harga barangan stabil. Ini sekaligus menunjukkan Ibn Taimiyyah turut mempertimbangkan nilai intristik atau dalaman logam supaya bersesuaian dengan nilai kuasa beli. Ini bertujuan mengelakkan orang ramai mengambil keuntungan dengan menjual logam atau membuat wang logam sendiri yang menambahkan wang dalam pasaran. Ibn Taimiyyah (1963) juga memberi pandangan beliau agar orang ramai tidak memulakan perniagaan dengan membeli timah dan kemudiannya meleburkan timah untuk dijadikan mata wang serta dikuti menjalankan perniagaan mata wang. Islahi (1992) menyatakan bahawa Ibn Taimiyyah menjelaskan perdagangan dalam mata wang mengakibatkan ketidakadilan pada masyarakat awam. Walau bagaimanapun, Ibn Taimiyyah tidak menghuraikan secara terperinci perkara ini, namun perdagangan mata wang akan menggalakkan pemalsuan mata wang dan mengakibatkan orang ramai hilang kepercayaan terhadap kadar tukaran tersebut seterusnya akan sebabkan berlaku inflasi dalam ekonomi. Perdagangan mata wang juga memberi kesan buruk dalam tempoh masa yang panjang kepada orang yang menerima bayaran yang tetap seperti penerima pencen dan orang yang menyewa kedai atau rumah. Ini kerana mereka mungkin menerima nilai yang lebih rendah akibat nilai mata wang yang tidak stabil. Logam yang baik akan mengalir keluar negara kerana logam tersebut mempunyai nilai yang lebih tinggi. 
Hal ini juga telah dibincangkan oleh al-Ghazali yang sangat bertegas mengenai larangan mata wang bercampur dalam pasaran. Ini menunjukkan al-Ghazali telah cuba untuk mengawal jumlah kuantiti mata wang yang berada dalam pasaran. Teori kuantiti wang ini juga mula menerima penambahbaikan dengan pandangan Ibnu Taimiyyah yang mencadangkan agar bayaran gaji pekerja dibayar dengan menggunakan wang daripada baitulmal yang merupakan perbendaharaan negara pada ketika itu. Tujuan Ibn Taimiyyah ialah untuk mengawal kuantiti yang berada dalam pasaran. Sekiranya pekerja dibayar dengan menggunakan logam tembaga, maka ini akan menyebabkan kuantiti wang terus bertambah dalam pasaran. Peningkatan dalam kuantiti mata wang akan menyebabkan inflasi dan ketidakstabilan nilai mata wang. Pada ketika itu, Baitul Mal merupakan institusi yang memegang sejumlah besar kekayaan negara termasuk mata wang. Ini bererti gaji yang dibayar menggunakan wang daripada baitulmal merupakan sebahagian mata wang yang beredar dalam pasaran. Ini jelas dapat mengelakkan pertambahan kuantiti wang dalam pasaran secara tidak terkawal.

Islahi (1992) membincangkan tokoh seterusnya yang merupakan anak murid kepada Ibnu Taimiyyah iaitu Ibn Qayyim yang cuba menjelaskan mengapa hanya emas, perak, dan bahan makanan utama sahaja dilarang pertukaran nilai yang berlainan dan tertangguh. Ibn Qayyim menyatakan bahawa rahsia di sebalik larangan ini kerana wang akan kehilangan nilainya dan makanan pula akan hilang peranannya untuk memberi diet yang sihat kepada manusia. Selain itu, Ibn Qayyim cuba mengkaji dan menjelaskan mengapa hanya logam tertentu iaitu emas dan perak serta makanan ruji seperti gandum dan beras sahaja dilarang melakukan penukaran yang berbeza jumlah dan masa. Beliau menyatakan bahawa ini disebabkan pertukaran yang tidak sama kuantiti bagi mata wang emas dan perak mengakibatkan fungsi utama mata wang sebagai suatu barangan yang mempunyai nilai untuk pertukaran akan musnah. Begitu juga dalam masalah larangan pertukaran barangan yang tidak sama jumlahnya disebabkan ia akan mengganggu fungsi utama iaitu sebagai keperluan diet dan tenaga kepada orang ramai. Perkara utama dalam transaksi ekonomi ialah untuk mendapatkan barangan dan perkhidmatan. Fungsi utama wang yang sangat penting ialah sebagai alat pertukaran dan penentu nilai barangan. Jika transaksi pertukaran yang tidak sama dengan jumlah kuantiti ini dibenarkan, ianya akan mengganggu fungsi asal wang dan akan mewujudkan golongan yang mengumpul dan memonopoli dua jenis komoditi ini iaitu logam emas dan perak serta bahan makanan asasi manusia.

\subsection{PERBANDINGAN PERANAN WANG MENURUT EKONOMI KONVENSIONAL DAN AL-GHAZALI}

Dari sudut fungsi wang, pandangan al-Ghazali dan pemikir ekonomi konvensional mempunyai persamaan iaitu wang sebagai medium pertukaran dan bertujuan untuk mengukur nilai yang merupakan fungsi utama mata wang. Nicholson (1998) menjelaskan bahawa kedua-dua fungsi ini juga diakui bertujuan untuk mengatasi masalah dalam sistem barter. Namun begitu, terdapat beberapa perbezaan terhadap fungsi wang yang lain iaitu ekonomi konvensional menyatakan bahawa wang berfungsi sebagai penyimpan nilai. Fungsi penyimpan nilai digunakan oleh ekonomi konvensional untuk menentukan sama ada memegang wang atau bon seterusnya menggambarkan aktiviti spekulasi dalam kewangan konvensional. Manakala al-Ghazali menolak wang sebagai penyimpan nilai kerana mengelakkan berlaku aktiviti perdagangan wang yang melibatkan aktiviti riba yang jelas bertentangan dengan al-Quran dan al-Sunnah. Al-Ghazali lebih menekankan bahawa wang bertujuan untuk mendapatkan barangan lain dan bukannya kerana faktor nilai dalaman sendiri sepertimana yang telah diperjelaskan sebelum ini. Dalam keadaan ekonomi semasa, pendekatan al-Ghazali yang tidak bersetuju bahawa wang sebagai penyimpan nilai bertujuan mengelakkan berlaku aktiviti spekulasi mengenai nilai mata wang. 
Dalam masalah jenis mata wang, al-Ghazali banyak membincangkan jenis wang daripada emas dan perak yang dikenali sebagai dinar dan dirham. Beliau menjelaskan bahawa mata wang jenis ini telah digunakan pada zaman beliau. Tetapi al-Ghazali menyatakan bahawa mata wang boleh digunakan dalam bentuk 'syakku' atau apa sahaja asalkan wang tersebut diperakui oleh pemerintah. Ini bermakna al-Ghazali tidak menolak mata wang kertas seperti yang digunakan dalam transaksi ekonomi pada hari ini. Malahan, tokoh pemikir ekonomi Islam selepas itu iaitu Ibn Khaldun telah menjangka bahawa mata wang akan berubah menjadi wang kertas tetapi beliau menjelaskan bahawa setiap mata wang tersebut perlu mempunyai sandaran emas dan perak. Manakala, masalah wang kertas atau wang fiat pada ketika ini tidak mempunyai apa-apa sandaran menyebabkan nilai mata wang tidak stabil. Ketiadaan apa sandaran ini menyebabkan kesukaran untuk mengawal jumlah penawaran dalam pasaran. Cantillon (1968) menjelaskan apabila adanya terlalu banyak wang dalam pasaran, tingkah laku agen ekonomi juga akan berubah dan menyebabkan masalah ekonomi seperti inflasi. Dalam persamaan pertukaran Fisher, wang merupakan alat pertukaran tetapi dalam persamaan Cambridge, wang lebih berperanan sebagai alat penyimpan nilai sebagai nisbah pendapatan atau keluaran yang dipegang dalam bentuk wang. Perubahan konsep ini yang membolehkan persamaan Cambridge ditulis dalam bentuk penawaran dan permintaan terhadap wang. Pada peringkat permulaan, Irving Fisher begitu menekankan wang sebagai alat pertukaran sepertimana dikemukakan oleh al-Ghazali sebelum itu. Namun, pandangan tersebut mula berubah kepada wang berperanan sebagai penyimpan nilai sepertimana yang dikemukakan oleh persamaan Cambridge (Humphrey, 1997).

Alfred Marshall merupakan tokoh yang dikaitkan dengan teori kuantiti wang moden (Humprey, 2004) dan kemudiannya diikuti oleh Friedman (1987). Pandangan yang dikemukakan sarjana ekonomi konvensional telah menunjukkan kenaikan kadar bunga sama ada dalam bon atau ekuiti serta jangkaan perubahan harga akan mengurangkan permintaan wang. Permintaan wang dilihat sebahagian daripada permintaan untuk kekayaan. Keadaan ini menunjukkan telah mula wujud unsur aktiviti spekulasi dalam kewangan. Dalam masalah wang bercampur, al-Ghazali secara jelas menekankan bahawa kewujudan mata wang akan memberi kesan buruk dalam ekonomi. Beliau telah menyatakan tindakan yang sepatutnya dilakukan apabila berlaku masalah mata wang bercampur sepertimana yang telah dibincangkan sebelum ini dalam subtopik 5.2. Pandangan al-Ghazali ini kemudiannya secara tidak langsung telah diakui oleh ekonomi konvensional dengan adanya teori Greshaw Law yang mengatakan "Bad Money drives out good money". Hanson (1970) menyatakan bahawa teori kewangan membincangkan bahawa jika dalam satu negara mempunyai dua jenis mata wang yang beredar iaitu mata wang yang tulen dan bercampur, maka mata wang yang bercampur sahaja yang akan digunakan dalam pasaran. Hal ini seterusnya akan menyebabkan kehilangan mata wang tulen. Dalam masalah ini, jelas menunjukkan bahawa terdapat persamaan pandangan yang dinyatakan oleh al-Ghazali bahawa apabila terdapat dua jenis mata wang yang berbeza bahannya, maka kewujudan mata wang bercampur akan menyebabkan individu akan bertindak menyimpan mata wang yang baik dan hanya menggunakan mata wang yang kurang sehingga menyebabkan wang baik hilang dalam pasaran.

\subsection{PENDEKATAN KEWANGAN AL-GHAZALI DALAM KEWANGAN SEMASA}

Malaysia merupakan sebuah negara yang mengamalkan dasar ekonomi campuran iaitu semua agen ekonomi bebas menjalankan aktiviti tetapi sentiasa melibatkan campur tangan kerajaan. Namun begitu, Malaysia seringkali mengalami pelbagai masalah ekonomi contohnya masalah inflasi yang menyebabkan kenaikan tingkat harga umum barangan dan perkhidmatan. Antara langkah yang perlu dilakukan kerajaan ialah menyekat aktiviti penimbunan wang dan penguasaan sumber modal oleh segolongan pihak sahaja sepertimana larangan al-Ghazali terhadap penimbunan emas dan perak oleh 
orang ramai. Kerajaan perlu menggalakkan persaingan yang lebih sihat antara industri untuk menghasilkan produktiviti yang tinggi, permodenan teknologi, dan daya saing industri dari segi harga produk. Hal ini bertujuan mengekalkan jumlah penawaran wang seimbang dengan penghasilan produk barangan bagi mengatasi masalah inflasi akibat lebihan jumlah wang dalam pasaran untuk mendapatkan produk yang sedikit. Selain itu, kerajaan juga menjalankan usaha-usaha tertentu melalui agensi seperti Lembaga Kemajuan lkan Malaysia (LKIM), Lembaga Pemasaran Pertanian Persekutuan (FAMA), dan badan-badan berkaitan dengan memberi galakan untuk meningkatkan kapasiti pengeluaran makanan. Pengguna juga perlu memainkan peranan bagi mengurangkan kadar inflasi sehingga mencapai matlamat inflasi sifar. Antara contoh yang boleh dilakukan oleh pengguna ialah mengurangkan paras perbelanjaan dengan membeli barangan yang diperlukan sahaja. Tindakan cemas para pengguna yang membeli barangan dalam kuantiti yang banyak dalam keadaan inflasi ini juga boleh memburukkan lagi keadaan. Pengguna perlu bertindak bijak dengan merancang pembelian mereka dengan baik dengan dapatkan nilai barangan yang sepadan dengan nilai wang serta mengelakkan perbelanjaan yang berlebihan terutama barangan yang tidak diperlukan.

Kegawatan ekonomi yang melanda Malaysia pada tahun 1997, 1998 yang terbaru 2014 telah memberikan impak terhadap ekonomi Malaysia. Krisis tersebut adalah berpunca daripada serangan mata wang negara yang telah mengakibatkan kejatuhan nilai ringgit Malaysia dan yang terkini kesan daripada kejatuhan ekonomi serantau serta penurunan harga minyak mentah dunia. Norhaziah dan Hanim (2006) menyatakan bahawa pada tahun 1998 ekonomi negara mencapai pertumbuhan negatif sebanyak 7.5 peratus dan jumlah hasil Kerajaan Persekutuan telah berkurangan pada tahun 1998 sebanyak RM9 ribu juta. Selain daripada itu, nilai pasaran modal juga telah berkurangan dari RM917 ribu juta dalam tahun 1997 kepada RM309.12 ribu juta pada 8 Jun 1998 dan ini menunjukkan pengurangan capitalization sebanyak lebih RM600 ribu juta. Pada tahun 1997, kerajaan telah menubuhkan tiga badan khas iaitu Pengurusan Danaharta Nasional Berhad, Danamodal Nasional Berhad, dan Jawatankuasa Penyusunan Semula Hutang Korporat (CDRC) untuk membantu syarikatsyarikat yang mengalami masalah kewangan alibat dari krisis kemelesetan ekonomi yang dihadapi oleh negara pada ketika itu.

Secara umumnya, apabila berlakunya masalah kemelesetan ekonomi. Maka, kegiatan pengeluaran juga akan terjejas kerana berlakunya masalah kekurangan modal dalam pasaran. Kegawatan ini telah menyebabkan kejatuhan permintaan swasta sama ada berbentuk pelaburan mahupun penggunaan. Di sinilah pentingnya peranan campur tangan kerajaan dalam mengatasi permasalahan tersebut dan ini adalah bersesuaian dengan cadangan serta saranan yang dicadangkan oleh al-Ghazali. Di Malaysia, semasa berlakunya kegawatan ekonomi, kerajaan akan menambahkan jumlah perbelanjaan awam serta dasar kewangan juga akan dilonggarkan dengan mengurangkan kadar faedah dengan tujuan untuk menggalakkan orang ramai meminjam dan seterusnya menambahkan wang dalam pasaran dengan tujuan untuk menggerakkan serta mengaktifkan pasaran yang lembap pada ketika itu. Ahmad Mansur (2009) berpendapat apabila berlakunya kelembapan ekonomi, masyarakat seharusnya digalakkan untuk melaburkan wang mereka dan bukannya membekukan aliran wang kerana pembekuan wang tidak dapat membantu dalam menjana ekonomi negara. Semasa berlakunya kemelesan ekonomi pada tahun 2008 dan 2009 kerana turut melancarkan pakej ransangan berjumlah 60 bilion ringgit untuk tempoh dua tahun tersebut.

Seperti yang telah dilihat pada situasi masa kini, negara barat yang kebanyakannya mengamalkan sistem ekonomi kapitalis tidak mengiktiraf sebarang campur tangan kerajaan dalam ekonomi. Walau bagaimanapun, ketika berlakunya kemelesan ekonomi dunia sebelum ini, kerajaan Amerika Syarikat turut menggunakan kaedah suntikan modal bagi menggerakkan ekonomi mereka dan ini hakikatnya telah bertentangan dengan dasar ekonomi kapitalis yang tidak membenarkan campur tangan kerajaan dalam ekonomi mereka. Walau bagaimanapun, pihak berkuasa Amerika Syarikat turut 
mengambil tindakan untuk campur tangan untuk meningkatkan semula pertumbuhan ekonomi Amerika Syarikat. Ahmad Mansur (2009) menyatakan bahawa jika dianalisis dengan lebih mendalam, ekonomi Islam merupakan sistem ekonomi terbaik jika dibandingkan diantara sistem ekonomi yang lain seperti kapitalis dan sosialis. Islam merupakan agama yang sentiasa mengajak manusia kearah untuk bersederhana dalam melakukan setiap perkara. Muhammad Abdul Mannan (2007) pula menjelaskan jika berlakunya campur tangan kerajaan secara berlebihan seperti dalam ekonomi sosialis, ia akan mengakibatkan sistem ekonomi tidak dapat berkembang dengan baik kerana berlakunya kebergantungan secara sepenuhnya terhadap kerajaan dan ini tidak memberikan kesan yang baik terhadap pembangunan ekonomi kerana tiadanya inisiatif untuk memajukan perusahaan masingmasing secara kreatif dan kritis. Berdasarkan pendekatan al-Ghazali, campur tangan pemerintah merupakan satu cara atau alternatif untuk mengawal kegiatan ekonomi sesebuah negara. Al-Ghazali menekankan tentang peranan pemerintah dalam mengawal pengeluaran wang. Namun, selaras dengan perkembangan ekonomi, peranan pemerintah dalam campur tangan ekonomi dapat diperluaskan bersesuaian dengan keadaan ekonomi semasa. Walau bagaimanapun, ini adalah satu bentuk cadangan yang memerlukan kajian lanjut dalam konteks ekonomi semasa.

\subsection{KESIMPULAN}

Berdasarkan perbincangan kajian ini mendapati tempoh masa karya penulisan al-Ghazali bermula 1058 hingga 1111 dan diikuti tokoh pemikir selepas beliau seperti Ibn Khaldun bermula 1332 hingga 1406 mendahului dalam mengemukakan teori berkaitan ekonomi kewangan. Teori berkaitan ekonomi kewangan kemudiannya mula diubahsuai oleh pemikir daripada ekonomi konvensional seperti Irving Fisher pada 1867 hingga 1947, Alfred Marshall bermula 1871 hingga 1826, dan Friedman bermula 1945 hingga 1980 yang pada mulanya bersetuju dengan pandangan al-Ghazali bahawa wang sebagai alat pertukaran dan alat pengukur nilai, akan tetapi turut menambah fungsi wang sebagai alat untuk tujuan spekulasi bagi mendapatkan kekayaan. Namun begitu, tambahan fungsi wang sebagai alat untuk spekulasi ini turut mengundang masalah ekonomi wang lain termasuklah inflasi. Berdasarkan tempoh masa penulisan menunjukkan pemikiran ekonomi Islam telah mendahului dalam pembentukan teori kewangan dalam ekonomi kemudian barulah diikuti oleh penulisan daripada sarjana-sarjana ekonomi konvensional. Bagi pendokong kehormanian dan kesaksamaan dalam ekonomi kewangan, idea dan pandangan al-Ghazali masih boleh diketengahkan sebagai salah satu idea dalam menguruskan kewangan dalam aktiviti ekonomi. Namun begitu, pemikiran al-Ghazali ini hanya bersifat fundamental dan memerlukan interpretasi dan analisis yang mendalam untuk disesuaikan dalam konteks ekonomi semasa. Rujukan daripada pembuktian al-Quran dan al-Sunnah serta ijtihad pemikiran sarjana terdahulu boleh diumpamakan sebagai bahan-bahan asas dalam menyediakan sebuah sistem ekonomi yang adil. Akan tetapi, kajian dan analisis golongan sarjana masa kini perlu terus dijalankan bagi mencapai objektif utama dalam ekonomi iaitu al-falah bermaksud kejayaan ekonomi di dunia dan di akhirat. 


\section{Rujukan}

Abu Hamid Al-Ghazali, Abu Hamid. (t.th) Ihya Ulumuddin. Jilid Ke-4. Beirut: Darul Nadwah.

Adiwarman, A. Karim. (2002). Ekonomi Islam: Suatu Kajian Ekonomi Makro. Jakarta: IIIT Press.

Ahmad Dimyati. (2008). Teori Kewangan Islam: Metodeologis Terhadap Teori Kewangan Al-Ghazali. Yogyakarta: UII Press.

Ahmad Mansur. 2009. Konsep Uang dalam Perspektif Ekonomi Islam dan Ekonomi Konvensional. AlQānūn 12(10):1-22.

Ahmad Shalabi. (1974) Masu'ah 'an-Nuzum wa Al-Hadharah Al-Islamiyyah: Al-Siyasah wa Al-Iqtisad fi al-Tafkir Al-Islami. Ed. Ke-3. Mesir: Maktabah An-Nahdah Al-Misriyyah.

Aidit Ghazali. 1991. Islamic Thinkers On Economics, Administration And Transaction. Jil 1. Kuala Lumpur: Quill Publishers.

Al-Farra, Abu Ya'la Muhammad Ibn Hussien. (1994). Al-Ahkam As-Sultaniyyah. Surabaya: T.Pt.

Al-Durayni, Fathi. (1988). Nazariyyat al-Ta'asuffi Isti'mal al-Haq. Beirut: Mu'assasah al-Risalah.

Al-Misri, Rafiq Yunus. (1981). Al-Islam Wa al-Nuqud. Jeddah: International Centre For Research In Islamic Economics, 1981).

Cantillon, R. (1968). Essay On The Nature Of Trade, in The Controversy Over The Theory Of Money, Ed. Edwin Dean. Massachusetts: Columbia University: 2-8.

Ghazanfar, S. M. (2000). The Economics Thought Of Abu Hamid Al-Ghazali And St Thomas Aquinas: Some Comparative Parallels And Link. History Of Political Economy 34 (4), 858-885.

Friedman, M. (1987). Quantity Theory of Money, In The New Palgrave: A Dictionary of Economics. John Eatwell, Murray Milgate, and Peter Newman, ed., vol. 4, pp. 3-20. New York: Stockton Press.

Hanson, J. L. (1970). Monetary Theory And Practices. Ed. Ke-4. London: Macdonald And Evans LTD.

Hasan Ibrahim. (1979). Tarikh al-Islam, al-Siyasi wa al-Dini wa al-Thaqafi wa al-Ijtima'i. Edisi Ke-7 Kaherah: Maktabat Al-Nahdah Al-Misriyah.

Humphrey, T. M. (1997). Fisher and Wicksell on the Quantity Theory. Federal Reserve Bank of Richmond Economic Quarterly 83(4), 71-88.

Humprey, T. M. (2004). Alfred Marshall and the Quantity Theory of Money. Federal Reserve Bank of Richmond Working Paper No. 04-10, 1-13.

Ibn Khaldun. (2005). The Muqaddimah: An Introductory To History. Princeton: Princeton University Press.

Ibn Miskawaih. (1964). Risala fi Mahiyat al-'Adl li Miskawaih. Leiden : E.J. Brill.

Ibn Qayyim. (t.th). I'lam Al-Muwaqqi'in 'An Rabb Al-'Alamin. Jil. Ke-1. Beirut: Dar Al-Kutub Al'Ilmiyyah.

Ibn Taimiyyah. (1963). Majmu’ Fatawa Shaikh Al-Islam. Riyadh: Matabi’ Al-Riyad.

Islahi, Abdul Azim. (1992). "Economic Thought Of Ibn Taimiyyah," In Reading In Islamic Economics Thought, Aidit Ghazali, ed.. Petaling Jaya: Longman Malaysia: 119-156.

Joni Tamkin Borhan. (2002). Metodologi Ekonomi Islam: Suatu Analisis Perbandingan. Jurnal Usuluddin 15: 73-88.

Lombard, M. (1975). The Golden Age Of Islam (Holland: North Holland Publishing, 1975). 
Muhammad Abdul Mannan. (2007). Ekonomi Islam: Teori dan Praktis (Asas-Asas Ekonomi Islam). AS Noordeen: Kuala Lumpur.

Nicholson, W. (1998). Macroeconomics Theory: Basic Principle And Extensions. Ed. Ke-17. T.Tp: The Dryden Press.

Noraine Abu. (2007). Biografi Imam Al-Ghazali: Hujjattul Islam dan Pembaru Kurun Ke-5 (450-505). Kuala Lumpur: Jasmin Enterprise.

Norhaziah \& Hanim. (2006). Penstrukturan Semula Syarikat Awam: Kajian Kes Terhadap Syarikat Tersenarai Di Bursa Malaysia (BSKL). Seminar MFA, Fakulti Ekonomi dan Muamalat Kolej Universiti Islam Malaysia 2006, hlm 1-21.

Sadeq, A. H. M. (1992). Al-Ghazali On Economics Issues And Some Ethico-Juristic Matter Having Implication For Economics Behavior, in Reading In Islamic Economics Thought, Ed. Aidit Ghazali. Petaling Jaya: Longman Malaysia: 88-110.

Sattar, M. A. (1968). Ibn Khaldun's Contribution To Economics Thought In Contemporary Aspects Of Economics Thinking In Islam. Proceedings Of The Third East Coast Regional Conference Of The Muslim Student's Association Of The United States And Canada April 1968, 109-115.

Siddiqi, Muhammad Nejatullah. (1992). Recent Works On Historyof Economics Thought In Islam: A Survey. In Reading In Islamic Economics Thought, Ed. Aidit Ghazali. Petaling Jaya: Longman Malaysia: 33-58.

Zainal Abidin Ahmad. (1979). Dasar-Dasar Ekonomi Islam. Jakarta: Penerbit Bulan Bintang. 